\title{
INTEGRATED GEOMATIC TECHNIQUES FOR THE LOCALIZATION AND GEOREFERENCING OF ANCIENT HERMITAGES
}

\author{
V. Baiocchi, M. Onori, M. Scuti \\ Sapienza University of Rome, DICEA, 00184 Rome, Italy - (valerio.baiocchi, matteo.onori)@uniroma1.it
}

KEY WORDS: UAV, Photogrammetry, GNSS, SfM, 3D modelling, Cultural Heritage, Hermitages, Georeferencing.

\begin{abstract}
:
Historical maps represent an important source of geographical information. The changes occurred over time can be extrapolated from them, especially if their geometric accuracies match those achievable with modern survey techniques. An 1820 map belonging to the Gregorian Cadastre provides the position of seven hermitages belonging to the monastery of Fara in Sabina (Italy). Just three of them are nowadays visible, while the others may have been covered by thick vegetation or been destroyed during the Second World War. The paper proposes the integration of geomatic techniques for the localization of the lost hermitages. To do so, Structure from Motion (SfM) algorithms were applied to UAV imagery to produce an orthophoto of the area. In addition, a GNSS survey was carried out using a professional and a low-cost receiver to correctly georeference the photogrammetric products. An accuracy assessment was then performed to evaluate the performance of the u-blox board in real applications. The accuracies obtained with the low-cost receiver indicates a possible more widespread utilization of these new devices. Subsequently, the comparison between the orthophoto and the cadastral map have been detailed. A weak correspondence between the position of the hermitages in the two maps have been observed. On the other side, the comparison led to the localization of two lost hermitages, with the other two being still undiscovered. This study has opened the door to an enhancement process of the monastery and to the rediscovery of the religious values of the hermitages.
\end{abstract}

\section{INTRODUCTION}

The object of the study is the monastery of Santa Maria dell'Orazione. It is located in Fara in Sabina, a municipality in the Province of Rieti and part of the Lazio Region. The religious complex was completed in 1678 and today it is inhabited by the Poor Clares Hermits, also known as the Second Order of Saint Francis. The monastic complex was bombed in 1944, during the Second World War, suffering serious damage. Only in the '70s, thanks to the efforts of Abbess Maria Beatrice, the monastery was rebuilt.

The monastery is nowadays an articulated structure with a strong religious appeal. It is home of a church, a refectory with its dormitory for pilgrims, a library and the cloistered area, inside which the nuns reside. It hosts the Museum of Silence as well, in which it is possible to go over the various stages of the life of a cloistered nun. Moreover, the presence of perfectly preserved bodies of seventeen nuns is object of interest both to the religious and scientific communities. Thorough investigation has recently shown that the bodies may belong to the first nuns that resided in the monastery during the XVII century.

Outside the monastery there is a steeply sloping land surrounded by a high perimeter wall. Part of the land was in the past used as a vegetable garden, while the other half was intended for religious functions. In fact, the latter hosted seven small hermitages, the importance of which is deduced from the religious ceremonial book drawn up for the monastery in 1679 . As emerges from this document, the hermitages played a central role in the life of the monastery. The nuns were in fact used to spend many hours each day praying inside the hermitages. Moreover, the nuns, led by the Abbess, undertook frequent liturgical processions that involved all the hermitages. This path, also known as the "Seven Churches" route, took place along the lines of the pilgrimage through the seven major roman basilicas. Starting from St. Peter, the most important of them, the procession would have also touched St. Paul, St. Sebastian, St. John, St. Cross, St. Lawrence and St. Mary Major basilicas. The document provides a detailed description of the hermitages, each of which was dedicated through a fresco to the corresponding basilica.

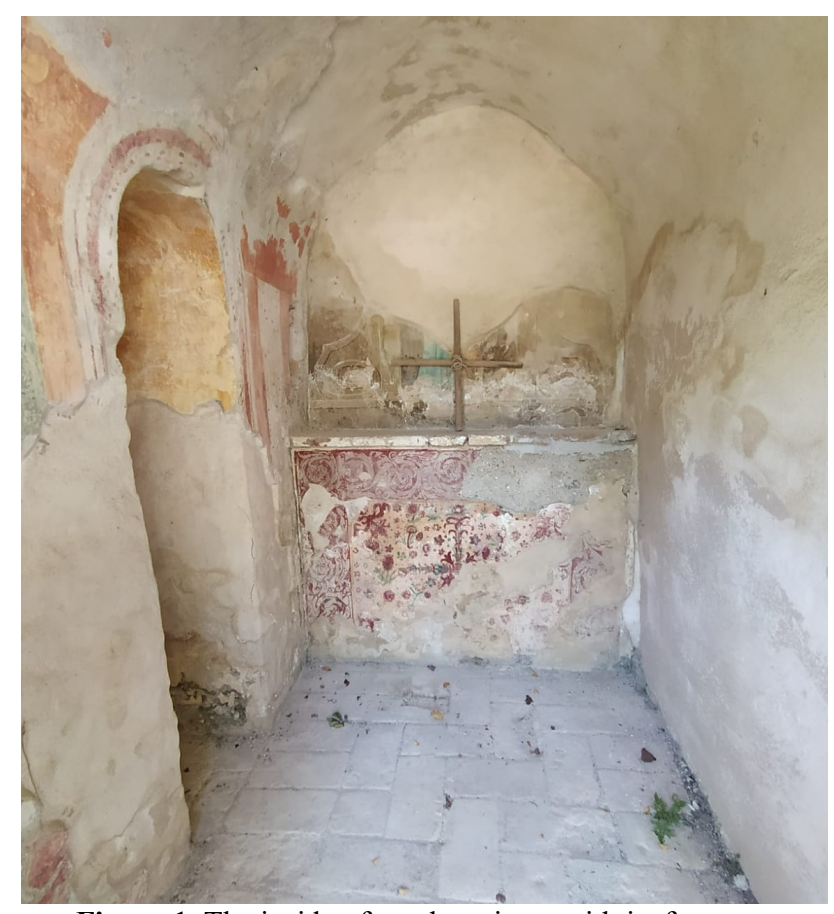

Figure 1. The inside of one hermitage with its frescoes.

The decrease of the monastic community over the centuries led the nuns to abandon the land, the religious processions and so 
the hermitages. Nowadays the nuns have knowledge of the position of only three hermitages. Despite they are still visible and accessible, these remaining hermitages are in a state of disrepair. The other four hermitages mentioned in the ceremional book might have been covered by thick vegetation or destroyed during the Second World War.

The purpose of this experiment is to locale and georeferencing the lost hermitages by integrating different geomatic techniques. From the one hand two types of GNSS receivers, a professional and a low-cost one, were used to measure GCPs over the study area. On the other hand, Structure from Motion (SfM) algorithms were used providing an almost fully automated elaboration of the photogrammetric imagery (Pan et al., 2019). The use of topographic instruments such as Terrestrial Laser Scanning (TLS), heavy and cumbersome, may result time consuming and impractical especially when the study area has a thick vegetation (Mancini et al., 2013). Lately new photogrammetric methodologies have been increasingly used within the scientific community. With the widespread of Unmanned Aerial Vehicles (UAV) equipped with low-cost sensors it is possible to acquire ultra-high resolution optical data in a short time (Brieger et al., 2019).

The same approach has been already used to survey Cultural Heritage (Chiabrando et al., 2015; Lo Brutto et al., 2014; Masiero et al., 2019). It has proven to be a flexible and a reliable way to produce georeferenced three-dimensional models and orthophotos of the surveyed area (Iheaturu et al., 2020). Accurate results have been achieved in different environments, even in the harsher ones (Alessandri et al., 2020). Once realized, the photogrammetric products will be compared with a 1:2.000 scale map made in 1820. It is part of the Gregorian Cadastre, which came into force under Pope Gregory XVII. The map represents the area around the monastery and the seven hermitages, which were once used by the nuns for their liturgical purposes. To perform an accurate assessment of the location of the hermitages based on the ancient map, high accuracy is required both from GNSS and photogrammetric surveys. In fact, the surveying techniques were already considerably accurate in XVIII century, at least in urban areas (Baiocchi et al., 2013).

Already available data, such as 1:5.000 scale Regional Technical Map, have a lower accuracy and does not give any information on the ancient or current location of the hermitages. In this paper we highlighted the main steps through which it was possible to locate two of the lost hermitages.

\section{SURVEY SETUP}

\subsection{GNSS Setup}

Before proceeding with the UAV imagery acquisition, a GNSS survey was set up. The photogrammetric products generated with SfM procedure are expressed in an arbitrary reference system. In order to georeferenced them, a GNSS survey was carried out to acquire a suitable set of Ground Control Points (GCP). The coordinates of a minimum of 3 GCPs must be known to perform a 3D Helmert transformation, but a higher number of GCPs is preferable to get more degrees of redundancy in georeferencing process and for accuracy evaluation (Alessandri et al., 2020).

During the GNSS survey planning, the choice of the points to acquire was strongly conditioned both by natural and artificial obstacles in the area. As said, the monastery possessions are characterized by the presence of dense and high vegetation. For this reason, most of the areas were inaccessible while GNSS receivers had problems for a good visibility of the satellites. Moreover, the presence of a high boundary wall along the external perimeter of the garden prevented the survey of more uniformly distributed GNSS points due to multipath phenomenon. The choice of the GCPs was then made to ensure the maximum visibility of the satellites for the GNSS antennas used in the survey. In addition, GCPs location over the study ensured an easy collimation in the UAV imagery during the subsequent processing phase. Of a total of 22 GCPs measured during the survey, 16 of them were chosen among natural and artificial points. The use of natural points makes it possible to reuse them for new surveys of the area, if needed. The remaining 6 GCPs were signalized with red and white noncodified targets in A3 size format $(29.7 \times 42 \mathrm{~cm})$. These targets were fixed to the ground in areas characterized by the absence of tree canopies.

The GNSS survey was then performed using two different receivers: a classical Topcon Legacy-E double frequency GPSGLONASS set in post-processing mode and a u-blox C099F9P-1 RTK application board. The latter belongs to a new generation of low-cost GNSS RTK, four constellation, double frequency receivers. The acquisition of GCPs has been carried out using both receivers on each point, whenever possible.

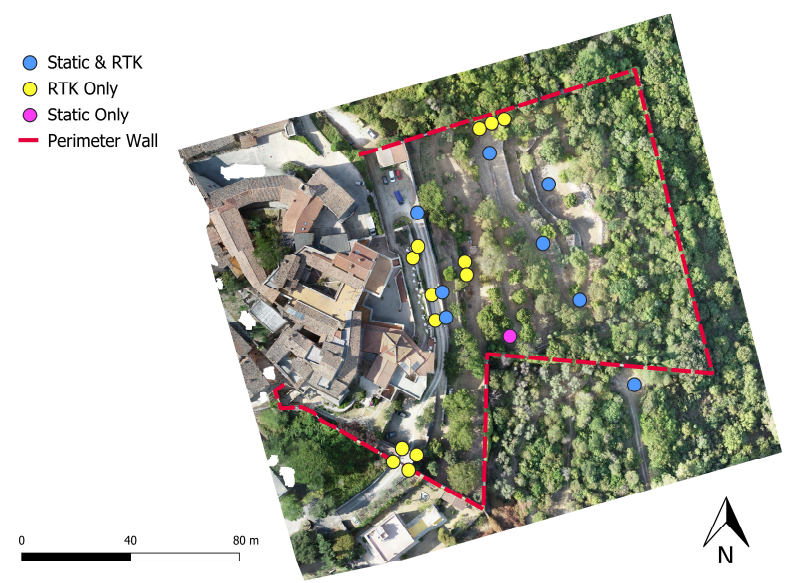

Figure 2. Distribution of GCPs over the survey area.

In fact, 21 of 22 GCPs were measured using u-blox receiver in RTK mode. It was not possible to obtain a fixed position solution of one of the markers due of a lack of $4 \mathrm{G}$ signal in that specific part of the garden. 8 GCPs were then measured using the Topcon Legacy-E double-frequency GNSS receiver and its antenna, set in post-processing mode. The receiver acquired for about 30 minutes on each target and on two of the natural points with a sampling interval of 1 second. In the end, 8 of the 22 GCPs were acquired both with u-blox application board and with the Topcon receiver (Fig. 2).

\subsection{GNSS Data Processing and Evaluation}

The data acquired with the Topcon receiver was post-processed exploiting the Lazio geodetic network management system. It is possible to download the observations from 18 permanent GNSS stations framed in the ETRF2000-RDN2008 (EPSG: 7792). The nearest of these stations, RIFL, is about $20 \mathrm{~km}$ far from the survey area. To achieve higher accuracy on the coordinates of the post-processed GCPs, a Virtual Reference Station (VRS) approach was used. The VRS observation data was computed by the Lazio geodetic network. It included RITI as a master station and ROUN, VALM, VIRB, FIUM, AMAP, FROS, LTNA and ACQU as auxiliary stations (Fig. 3).

The baselines were then elaborated using Topcon Tools ver. 8.0. To verify the reliability of the results obtained with the 
commercial software, the post-processing was later repeated with the open-source software RTK Lib ver. 2.4.2 (www.rtklib.com). Non-significant differences were observed.

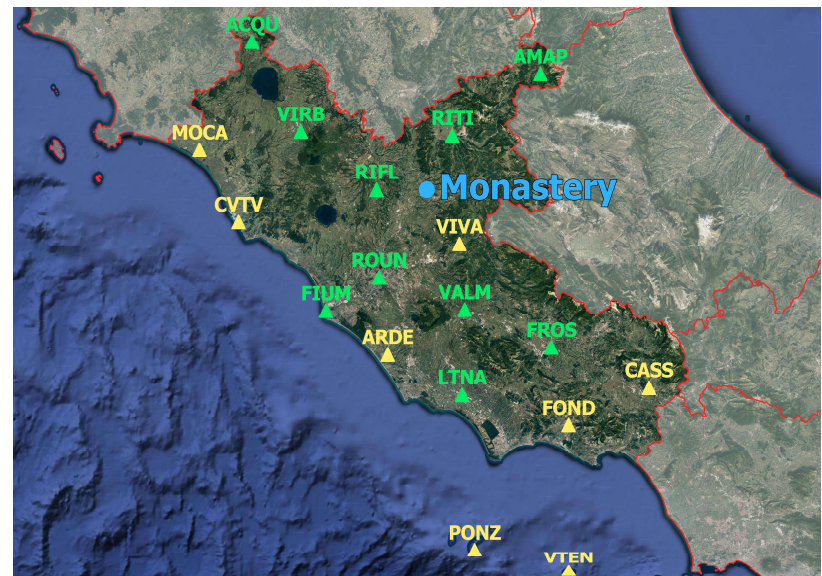

Figure 3. Regione Lazio GNSS network. The green stations were used in the computation of the VRS.

Subsequently, the coordinates of the GCPs were transformed in WGS84/UTM zone 33N (EPSG: 32633). The ellipsoidal heights were then converted into orthometric heights using the national geoid model, ITALGEO2005. The official algorithms provided for this geoid model, as implemented in the Geotrasformer software, have been used (Baiocchi et al., 2017). At this point the comparison between the coordinates collected with the two receivers on the same points is needed. By doing so, it is possible to verify if the low-cost receiver could guarantee high accuracies in real applications. From the one hand, similar results have been obtained in planimetry. On the other hand, bigger differences are observed between the elevation components measured with the two receivers (Tab. 1). The discrepancy in results may be in part influenced by lowcost antenna phase centre, which exact location and height in relation to the various constellations and frequencies has not yet been accurately calibrated. It should also be noted that in the control software of the board itself, the coordinates are displayed with an approximation of few decimals. In particular, the height is limited to decimetre accuracy.

This means that conducting further tests, the u-blox receiver acquiring in RTK mode may become a valid alternative to professional GNSS receivers. It can be exploited especially when the survey has to be swift and flexible.

\begin{tabular}{|c|c|c|c|}
\hline & $\boldsymbol{\Delta E}(\mathbf{c m})$ & $\boldsymbol{\Delta N}(\mathbf{c m})$ & $\boldsymbol{\Delta h}(\mathbf{c m})$ \\
\hline P1 & -3.2 & 1.8 & 9.5 \\
\hline P2 & 0.3 & 5.5 & 2.1 \\
\hline P3 & -2.4 & 5.6 & -37 \\
\hline P4 & 1.5 & 4.4 & -0.8 \\
\hline P5 & -0.9 & -0.8 & 16.7 \\
\hline P6 & -3.1 & -1.2 & -9.7 \\
\hline P7 & 1.7 & 1 & 1 \\
\hline RMSE & 2.1 & 3.5 & 16,2 \\
\hline
\end{tabular}

Table 1. Differences between Topcon and u-blox coordinates.

\subsection{Photogrammetric Setup}

Planning and performing a survey in areas characterized by man-made structures, dense vegetation and complex morphology may be challenging. A highly redundant and overlapping photogrammetric imagery is still recommendable (Sanz-Ablanedo et al., 2018). The area of interest has been surveyed using a DJI Phantom4 Pro quadcopter drone. A FC6310 camera with an $8.8 \mathrm{~mm}$ nominal focal length is mounted on the stabilized gimbal of the drone as well as a CMOS sensor with a pixel size of $2.4 \mu \mathrm{m}$. Pix4D FlightPlanner has been used to set up a fully automated UAV flight over the study area. Due to the complex conformation of the monastery, with its steeply sloping land, the drone flew between 50 and 90 meters. At the end of the acquisition 117 images with $5472 \mathrm{x}$ 3648 pixels were captured with a mean ground resolution of 25 $\mathrm{mm} / \mathrm{pix}$.

\section{SFM DATA PROCESSING}

\subsection{Photos Alignment and 3D Sparse Cloud}

The images acquired by the drone were loaded in Agisoft Metashape (ver 1.6.3. https://www.agisoft.com/). This software embeds SfM algorithms by which it is possible to generate the three-dimensional geometry of a scene from multiple overlapping photographs (Caroti et al., 2015). The software provides a structured workflow which main steps are represented by bundle block adjustment (BBA), camera alignment optimization and dense reconstruction of the scene geometry (Gonçalves et al., 2021). The first phase of the imagery processing is implemented in the software function Align Photos. It embeds BBA procedure with which both intrinsic camera parameters and extrinsic parameters are estimated. With the estimation of the external camera orientation parameters the position at which the photos were taken by the drone is reconstructed (Fig. 4). In addition, the software detects analogous points on the images and matches them into tie points. The alignment process, which was performed with the highest accuracy, generated a 3D sparse point cloud of 107.651 tie points with a RMS reprojection error of 0.58 pixels.

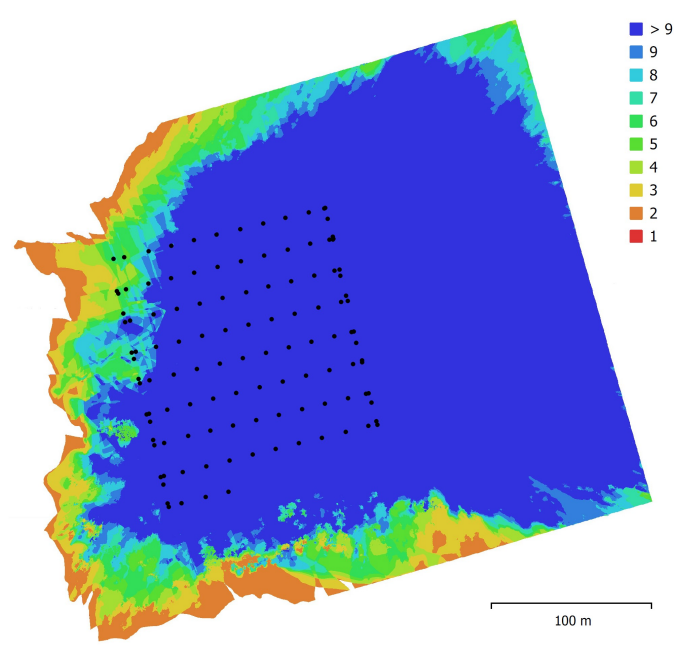

Figure 4. Camera locations and image overlap.

\subsection{Georeferencing Strategy: GCPs and CPs}

The sparse point cloud obtained with the alignment is expressed in an arbitrary reference system. Consequently, a georeferencing strategy is needed to carry out a 7 parameters $3 \mathrm{D}$ Helmert transformation, which consists of 3 translations, 3 rotations and a scaling factor. This process is performed together with the function Optimize Camera Alignment. The use 
of the coordinates of the points acquired during the geodetic survey is in this phase mandatory. If not, the software uses the roughly approximate coordinates provided by the GPS/GNSS point positioning receiver on board the drone with poor and sometimes unexpected results. All the points acquired during the GNSS survey have been loaded in the software to perform the optimization. In the case of points acquired both with Topcon and u-blox receivers, post-processed coordinates have been chosen above RTK ones. In fact, the coordinates obtained with Topcon receiver are supposed to be more accurate than the ones obtained with the u-blox receiver acquiring in RTK mode. Once the points are loaded in the software, the corresponding non-codified targets or natural points must be detected on the UAV imagery. Placing a marker on at least two aligned photos will make the software to automatically detect the same marker on the rest of the photos. Unfortunately, targets are often misidentified or not identified at all. Lighting conditions and shadows, as well as the presence of tree canopies, affect a proper target automatic detection. For this reason, a manual refinement of the markers location is required. Not to compromise the overall accuracy of the georeferencing process, not well identifiable markers have been unchecked on certain photos and thus unused for the computation.

With the markers placed on the corresponding targets or natural points in all the photos, it is necessary to set the accuracy with which the GCPs were acquired. In fact, the software includes a user-friendly workflow in which many processing parameters have default values (Ludwig et al., 2020). Moreover, it does not provide a distinction between planimetric and height accuracies, which are supposed to be different whatever the method used to calculate the coordinates is. The default accuracy provided by the software for the GCPs is 0.005 meters. Given the fact that GNSS receivers are less accurate for the elevation than for planimetry, it was necessary to set different values for the two components. For the points acquired with the Topcon receiver, values of $4 \mathrm{~cm}$ on the horizontal components and of $7 \mathrm{~cm}$ on the vertical component were assumed. Considering the nominal accuracy of the u-blox receiver acquiring in RTK mode, values of $4 \mathrm{~cm}$ and $10 \mathrm{~cm}$ were in this case chosen.

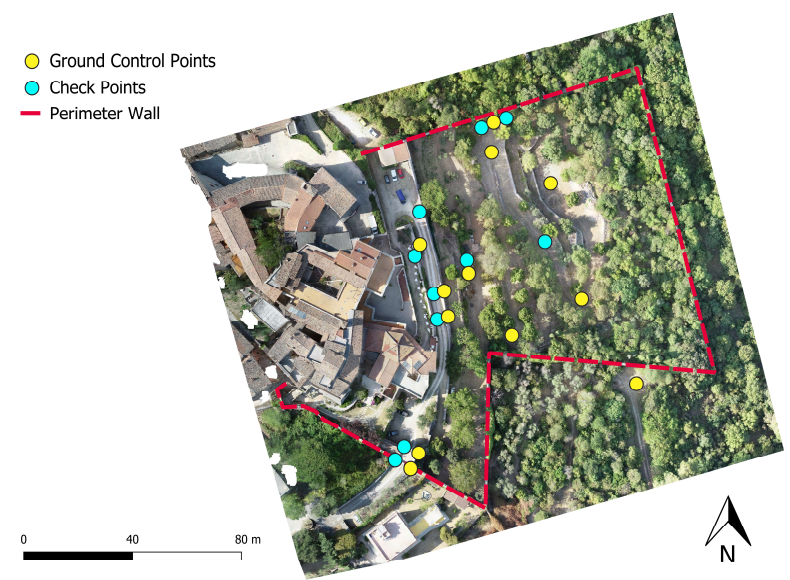

Figure 5. Distribution of GCPs and CPs over the survey area.

The georeferencing process was then performed dividing points in two main groups: 12 GCPs were used in optimization procedure, while the other 10 were set as Check Points (CP). This division is necessary for a subsequent evaluation both of precision and accuracy of the achieved products. The two groups have been formed to ensure the optimal distribution of GCPs and CPs over the survey area (Fig. 5). After the optimization process, the absolute orientation has been achieved and the $3 \mathrm{D}$ sparse cloud has been correctly georeferenced. The software reports a total RMSE of $0.068 \mathrm{~m}$ on the GCPs. On the CPs a value of $0.093 \mathrm{~m}$ was obtained (Tab. 2).

\begin{tabular}{|c|c|c|c|c|}
\hline Points & $\mathrm{X}(\mathrm{cm})$ & $\mathrm{Y}(\mathrm{cm})$ & $\mathrm{Z}(\mathrm{cm})$ & pix \\
\hline GCPs & 3.2 & 2.4 & 5.5 & 0.5 \\
\hline CPs & 3.9 & 3.7 & 7.5 & 0.9 \\
\hline
\end{tabular}

Table 2. RMSE in X, Y, Z of GCPs and CPs.

\subsection{Orthophoto and 3D Model Realization}

The following step, as provided in the workflow by the software, consists in the densification of the sparse cloud. A 3D dense cloud of 102 million points has been created using High Quality. Starting from the dense cloud, a Digital Elevation Model (DEM) with a cell size of $0.045 \mathrm{~m}$ was at this point generated (Fig. 6). It is equivalent to a Digital Surface Model (DSM) and it contains natural and artificial elements of the area such as trees and buildings. With the DEM it was consequently possible to elaborate an orthophoto of the survey area framed in the project reference system (Fig. 2 and Fig. 5).

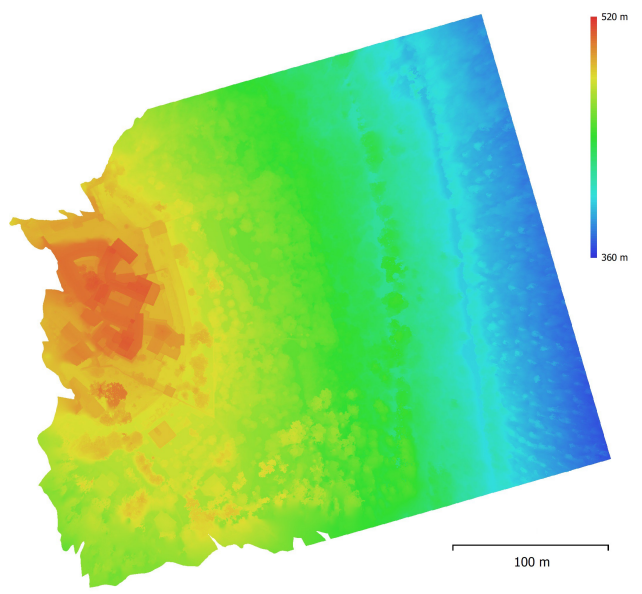

Figure 6. Digital Surface Model of the area.

Although the following step was not strictly necessary for the localization of the lost hermitages, the 3D model of the area was created. In fact, the latter will be part of the enhancement programme carried on by the nuns. Starting from the dense cloud, the polygonal mesh model of the surveyed area has been generated with a custom polygon count of 10 million faces. In the last part of the 3D model building, the resulting mesh has been textured using the dense cloud as source data. (Fig. 7).

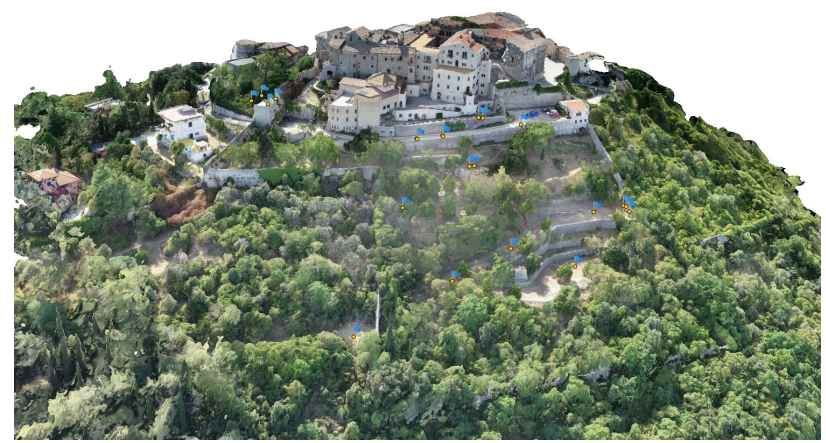

Figure 7. Tiled model of the survey area. 


\section{RESULTS AND CONCLUSIONS}

\subsection{Cadastral Map and Orthophoto Comparison}

The orthophoto was exported and loaded into the open-source software QGIS ver. 3.14 (https://www.qgis.org/it/site/). The orthophoto will serve as a basemap to correctly georeference the cadastral map. The latter was previously scanned in high quality to obtain a $5976 \times 5248$ pixels image. The comparison of the two maps is needed for the localization of the lost hermitages. In fact, the 1820 map provides the original position of the seven hermitages. At the same time, the position of the three hermitages known today has been measured during the GNSS survey and it is easily identifiable in the orthophoto. For this reason a good georeferencing process has to be performed not to lower the accuracy obtained both with the GNSS survey and with the orthophoto generation.

Firstly, a simple 4 parameters Helmert transformation, which consists of a simple roto-translation with a single isotropic scale factor, was performed. It was decided to test this algorithm to verify if the geometries on the old map were consistent with those on the current orthophoto. The process of georeferencing was performed collimating the edges of the perimeter wall. In fact, it is assumed that the wall has not undergone relevant size and shape changes since the monastery foundation. This first experiment showed that the forms and dimensions of the objects on the map were deformed compared to what can be expected from this cartography. This problem was already studied in previous research for large-scale maps of this period (Timár et al., 2011). Errors may be the result of a bad state of preservation of the map or an improper process of scanning acquisition, whose calibration parameters are unknown.

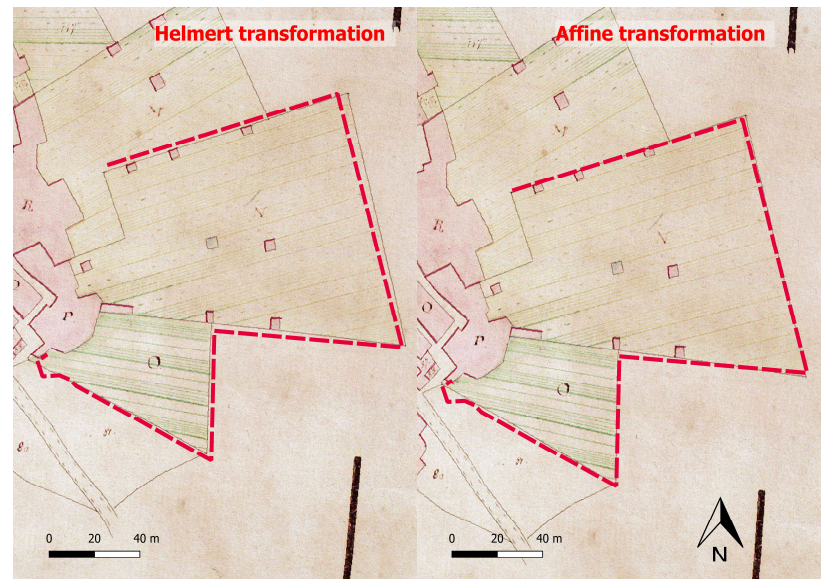

Figure 8. Comparison between Helmert and Affine transformations.

Once the 1820 cadastral map was georeferenced and expressed in WGS84/UTM zone 33N (EPSG: 32633), a shapefile containing the geometries of the hermitages have been created. The artesian well, which in the map is distinguishable by its blue fill colour from the seven pink hermitages, has also been mapped. The same operation has been done with the geometries in the orthophoto. The seven hermitages featured in the old map have been highlighted in orange and indicated by numbers. Yellow shapes and capital letters have been chosen to map geometries in the orthophoto (Fig. 9).

Even compensating for the effects of deformations on the boundary wall, which is considered as a reference, the positions of the visible hermitages on the cadastral map remains significantly distant from their current positions on the ground. A lack of correspondence is also observed between the two well, which positions differ by 10 metres. A weak correspondence between the set of geometries may be assumed just between hermitages 7 and C, 4 and B, and also between the two wells, although with considerably high planimetric distances.

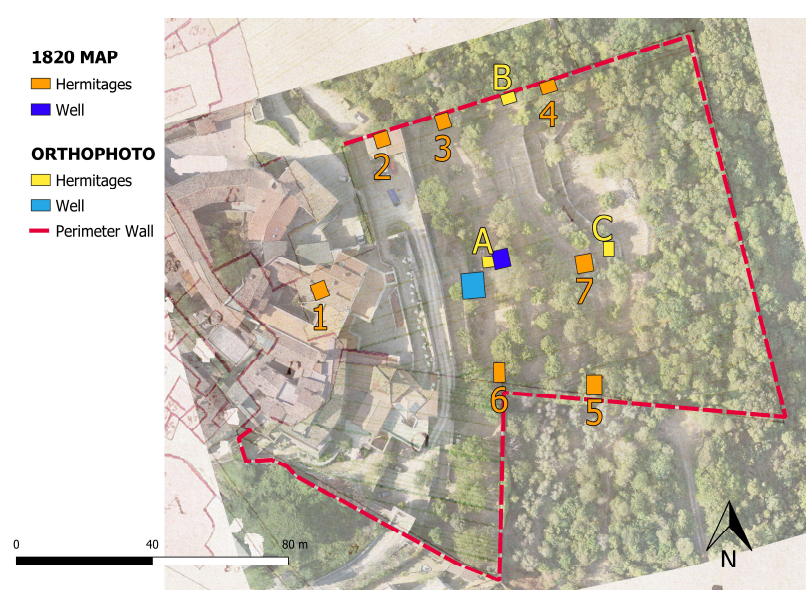

Figure 9. Comparison between hermitages positions.

This evidence may have two explanations. The first theory is that the hermitages are not the original ones but have been reconstructed later and in different positions. The second theory is that the topographical survey for the cadastral map has been carried out in a rough manner. The latter hypothesis would demonstrate a lower accuracy in the survey of details in ecclesiastical properties. This inaccuracy could perhaps be due to the difficult accessibility in a cloistered convent. However, this assumption contrasts with previous studies in which, at least in urban areas, this low accuracy was not observed.

A new in situ inspection of the area was then necessary to search for traces of the hermitages $1,2,3,6,5$. It is conceivable that the hermitage 1 , which nuns had always believed to be destroyed during the war, has been relocated in correspondence of hermitage A. Despite no evidence of the relocation has emerged so far, A is the only hermitage known today not to appear in the cadastral map. For this reason the hypothesis of a correspondence between the two mapped hermitages may be deepen with further investigations. No visible traces or foundations were found to prove the existence of hermitages 3 and 6.

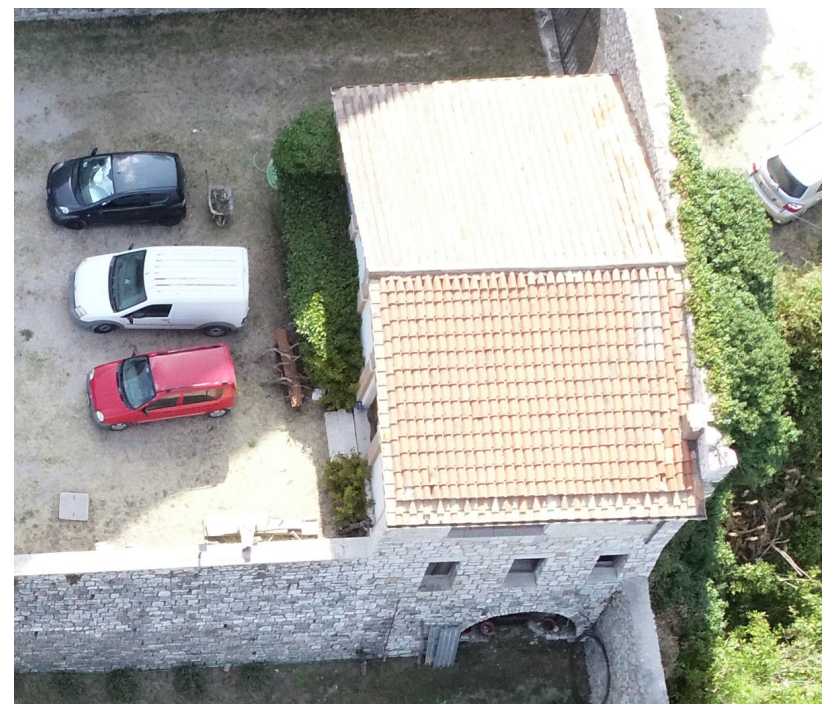

Figure 10. Hermitage 2 as seen in UAV imagery. 
Near the structure indicated with the number 5, a hermitage which was completely covered by vegetation has been found. The hermitage, of which the nuns had lost the traces, was not visible neither during the first survey nor in the photogrammetry products. Despite the presence of vegetation, the hermitage is in good condition and could be subjected to a complete restoration. Moreover, it was possible to identify the hermitage 2 with a little structure close to the main building of the monastery (Fig. 10). As emerged from the new in situ inspection, the hermitage has been converted into a storage some time after the cadastral map was made in 1820. Even though it has lost its religious connotations, the structure is the best preserved among the hermitages.

\subsection{Conclusions and Further Developments}

The use of integrated geomatic techniques allowed the study of the monastery possessions. The proposed methodology has led to the localization of two old hermitages which were forgotten by monastic community. From the one hand, SfM algorithms were applied to UAV imagery. Using a drone has made it possible to survey the area in a quick but precise manner. With an almost fully automated elaboration, the orthophoto and the 3D model of the area were then created. Unfortunately, the software used in the processing provides a structured workflow whose downside is to embed inaccurate default values to many important parameters.

On the other hand, a new generation low-cost receiver has been tested during the GNSS survey. Also in consideration of the two types of positioning mode chosen, the operational use of u-blox application board showed adequately accurate results. In fact, the photogrammetric products were georeferenced and later compared with an 1820 cadastral map, which initially was supposed to be more accurate. The professional and more expensive GNSS receiver still ensures higher accuracies in real applications. Its use may result unnecessary especially if the survey requires flexibility due to a complex morphology of the area. With a view to perform new surveys with the same instrumentation, further tests must be performed on longer times and on self-centering pillars to investigate the performance of the u-blox application board.

Subsequently, the comparison between historical cadastral cartography and high-resolution drone orthophotos has been done. It has shown discrepancies beyond the cartographic limits known at that time. It is possible that the Gregorian Cadastre is less accurate than observed in literature so far. It may be the consequence of a difficult access to the cloistered monastery during the XIX century. A second scenario deserves to be further investigated, possibly with the support of archaeological excavations. In fact, it is possible that the hermitages are not in their original position. They may have been moved or rebuilt from scratch after the Second World War. Moreover, the comparison of the orthophoto and the old cadastral map led to a better understanding of the religious processions that took place in the monastery garden. With the rediscovery of two old hermitages, the "Seven Churches" route has been reconstructed with the help of the nuns and historical sources. The five hermitages have become a central part of the monastic community again. In fact, they are a core part in the enhancement process of the monastery which involves the vegetable garden, the Museum of Silence and the library as well. New religious processions take place among the hermitages both with the nuns and the pilgrims. In addition, guided visits for tourists that illustrate the history of the monastery and its hermitages are now organized on a regular basis. A restoration work is being planned to save the old frescoes inside the hermitages.

\section{ACKNOWLEDGEMENTS}

The authors would like to thank the Abbess Chiara, Suor Barbara and all the Poor Clares Hermits for their hospitality and their kind help.

\section{REFERENCES}

Alessandri, L., Baiocchi, V., Del Pizzo, S., Di Ciaccio, F., Onori, M., Rolfo, M. F., and Troisi, S., 2020. The fusion of external and internal 3D photogrammetric models as a tool to investigate the ancient human/cave interaction: the La Sassa case study. Int. Arch. Photogramm. Remote Sens. Spatial Inf. Sci., XLIII-B2-2020, 1443-1450, https://doi.org/10.5194/isprsarchives-XLIII-B2-2020-1443-2020.

Alessandri, L., Baiocchi, V., Del Pizzo, S., Di Ciaccio, F., Onori, M., Rolfo, M.F., Troisi, S., 2020. A Flexible and Swift Approach for 3D Image-Based Survey in a Cave. Appl. Geomat., 1-15. https://doi.org/10.1007/s12518-020-00309-4.

Baiocchi, V., Lelo, K., Milone, M.V., Mormile, M., 2013. Accuracy of different georeferencing strategies on historical maps of Rome. Geographia Technica (1), 10-16.

Baiocchi, V., Camuccio, P., Zagari, M., Ceglia, A., Del Gobbo, S., Purri, F., Cipollini, L., Vatore, F., 2017. Development of a geographic database of a district area in open source environment. Geoingegneria Ambientale e Mineraria 151 (2), 97-101.

Brieger, F., Herzschuh, U., Pestryakova, L.A., Bookhagen, B. Zakharov, E.S., Kruse, S., 2019. Advances in the Derivation of Northeast Siberian Forest Metrics Using High-Resolution UAV-Based Photogrammetric Point Clouds. Remote Sens., 11, 1447. https://doi.org/10.3390/rs11121447.

Caroti, G., Martinez-Espejo Zaragoza, I., Piemonte, A., 2015. Accuracy assessment in structure from motion 3D reconstruction from UAV-born images: The influence of the data processing methods. Int. Arch. Photogramm. Remote Sens. Spat. Inf. Sci., XL-1/W4, 103-109. https://doi.org/10.5194/isprsarchives-XL-1-W4-103-2015.

Chiabrando, F., Donadio, E., Rinaudo, F., 2015. SfM for Orthophoto Generation: A Winning Approach for Cultural Heritage Knowledge. Int. Arch. Photogramm. Remote Sens. Spatial Inf. Sci., XL5/W7, 91-98. https://doi.org/10.5194/isprsarchives-XL-5-W7-91-2015.

Gonçalves, G., Gonçalves, D., Gómez-Gutiérrez, Á., Andriolo, U., Pérez-Alvárez, J.A., 2021. 3D Reconstruction of Coastal Cliffs from Fixed-Wing and Multi-Rotor UAS: Impact of SfMMVS Processing Parameters, Image Redundancy and Acquisition Geometry. Remote Sens., 13 (6), 1222. https://doi.org/10.3390/rs13061222.

Lo Brutto, M., Garraffa, A., and Meli, P., 2014. UAV platforms for cultural heritage survey: first results. ISPRS Ann. Photogramm. Remote Sens. Spatial Inf. Sci., Vol. II-5, 227-234. https://doi.org/10.5194/isprsannals-II-5-227-2014.

Ludwig, M., M. Runge, C., Friess, N., Koch, T.L., Richter, S., Seyfried, S., Wraase, L., Lobo, A., Sebastià, M.-T., Reudenbach, C., Nauss, T, 2020. Quality Assessment of Photogrammetric Methods-A Workflow for Reproducible 
UAS Orthomosaics. Remote Sens., 12, 3831. https://doi.org/10.3390/rs12223831.

Mancini, F., Dubbini, M., Gattelli, M., Stecchi, F., Fabbri, S., Gabbianelli, G., 2013. Using Unmanned Aerial Vehicles (UAV) for High-Resolution Reconstruction of Topography: The Structure from Motion Approach on Coastal Environments. Remote Sens., 5, 6880-6898. https://doi.org/10.3390/rs5126880.

Masiero, A., Chiabrando, F., Lingua, A.M., Marino, B.G., Fissore, F., Guarnieri, A., Vettore, A., 2019. 3d modeling of Girifalco fortress. Int. Arch. Photogramm. Remote Sens. Spatial Inf. Sci., XLII-2/W9, 473-478. https://doi.org/10.5194/isprsarchives-XLII-2-W9-473-2019.

Pan, Y., Dong, Y., Wang, D., Chen, A., Ye, Z., 2019. ThreeDimensional Reconstruction of Structural Surface Model of Heritage Bridges Using UAV-Based Photogrammetric Point $\begin{array}{llll}\text { Clouds. Remote } & \text { Sens., } & 11, & \end{array}$ https://doi.org/10.3390/rs11101204.

Sanz-Ablanedo, E., Chandler, J.H., Rodríguez-Pérez, J.R., Ordóñez, C., 2018. Accuracy of Unmanned Aerial Vehicle (UAV) and SfM Photogrammetry Survey as a Function of the Number and Location of Ground Control Points Used. Remote Sens., 10, 1606. https://doi.org/10.3390/rs10101606.

Timár, G., Baiocchi, V., Lelo, K., 2011. Geodetic datums of the Italian cadastral systems, Geographia Technica (1), 82-90.

Turner, D., Lucieer, A., Watson, C., 2012. An Automated Technique for Generating Georectified Mosaics from UltraHigh Resolution Unmanned Aerial Vehicle (UAV) Imagery, Based on Structure from Motion (SfM) Point Clouds. Remote Sens., 4, 1392-1410. https://doi.org/10.3390/rs4051392.

Iheaturu, C., Ayodele, E., Okolie, C., 2020. An Assessment of the accuracy of Structure-from-Motion (SfM) Photogrammetry for 3D terrain mapping. Geomatics, Landmanagement and Landscape, 2 , 65-82. http://dx.doi.org/10.15576/GLL/2020.2.65. 